Article

\title{
Assessing Social Value in Open Data Initiatives: A Framework
}

\section{Gianluigi Viscusi $^{1, *}$, Marco Castelli ${ }^{2}$ and Carlo Batini ${ }^{2}$}

1 École polytechnique fédérale de Lausanne (EPFL) - CDM MTEI CSI ODY 116 (Odyssea) Station 5, Lausanne CH-1015, Switzerland

2 Department of Informatics Systems and Communication (DISCo) - University of Milano-Bicocca, U14 Building Viale Sarca, 336, Milano 20126, Italy;

E-Mails: marco.castelli@disco.unimib.it (M.C.); batini@disco.unimib.it (C.B.)

* Author to whom correspondence should be addressed; E-Mail: gianluigi.viscusi@epfl.ch (G.V.); Tel.: + 41-216-930-018; Fax: +41-216-930-020.

Received: 4 March 2014; in revised form: 26 May 2014 / Accepted: 4 June 2014 /

Published: 19 August 2014

\begin{abstract}
Open data initiatives are characterized, in several countries, by a great extension of the number of data sets made available for access by public administrations, constituencies, businesses and other actors, such as journalists, international institutions and academics, to mention a few. However, most of the open data sets rely on selection criteria, based on a technology-driven perspective, rather than a focus on the potential public and social value of data to be published. Several experiences and reports confirm this issue, such as those of the Open Data Census. However, there are also relevant best practices. The goal of this paper is to investigate the different dimensions of a framework suitable to support public administrations, as well as constituencies, in assessing and benchmarking the social value of open data initiatives. The framework is tested on three initiatives, referring to three different countries, Italy, the United Kingdom and Tunisia. The countries have been selected to provide a focus on European and Mediterranean countries, considering also the difference in legal frameworks (civic law vs. common law countries).
\end{abstract}

Keywords: open data; social value; public value; assessment; classification

\section{Introduction}

Open data initiatives are characterized, in several countries, by a great extension of the number of data sets made available for access by public administrations, constituencies, businesses and other 
actors, such as, journalists, international institutions and academics, to mention a few. However, most of the open data sets rely on selection criteria, based on a technology-driven perspective, rather than on a focus on the potential public or social value of the data to be published. Several experiences and reports confirm this issue, such as, those of the Open Data Census. However, there are also relevant best practices. The benefits of open data may range from the political and social ones, such as increased transparency, accountability, participation and self-empowerment of citizens, to economic growth and stimulation of competitiveness and innovation, among others [1]. However, several socio-technical barriers, when not "myths", as claimed by Janssen et al. [1], prevent an appropriate selection of the data sets and a consequent effective exploitation of their benefits. Among the diverse "myths" that are worth mentioning are the ones concerning data disclosure and the simplistic, when not ideological, vision that even publishing public data can lead to an intensive use by constituencies and the realization of open government [1].

The aim of the research presented in this paper is to provide a classificatory framework, suitable for further support of the assessment of the social value of open government data initiatives. It is worth noting that, from a public value perspective prevailing in public administration, policy, as well as e-government studies, social value concerns the outcomes of public initiatives. However, we argue that it can be seen as an independent issue with regard to the planned goals of a public action. Apart from the diverse potential interpretation of what is "value" [2-4], considering the meaning of the term "social", it relates "to human society, the interaction of the individual and the group, or the welfare of human beings as members of society" [5]; whereas the term "public" is defined as "of, relating to, or affecting all or most of the people of a country, state, etc.; supported by money from the government and from private contributors, rather than by commercials; related to the impact on, motivating or calling for further government actions having a public value" ([6]; see also the extensive discussion on the meaning of "public" in [4]). Thus, while some public values are socially oriented [3], not all socially-oriented values may have an actual value for the public, as implemented in the government initiatives. To summarize, our perspective in this paper considers public values as having a push perspective from public administration to society. Thus, this implies an active action, and interests, by the central or local government, as well as a focus on their behavior; whereas we consider social values as emergent from the welfare state, thus having a potential, but not necessarily actualized, pull perspective towards public administration action and policies; and as a consequence, agreeing with the authors who point out that public values are not "an exclusive province of the government" [2]. Consequently, when the latter refers to social outcomes, we prefer to refer to it as a social value instead of adopting the sole public value term according to the distinction outlined above.

Taking these issues into account, it is our point that a classificatory framework, based on public or social value dimensions, is actually, neither provided in a systematic way, nor emphasized by open government data portals, which still mainly rely either on traditional e-government classification frameworks, such as the events of life or similar events, or by the target of administrative procedures and activities. In particular, having a social value-oriented classification may improve the understanding, by both citizens and policy makers, of the actual orientation of the initiatives to be planned, or already in place, as well as an informed choice of the data set to be published or worthy of access by citizens. Furthermore, such a classification may provide an interpretive basis for an assessment of the value of the open government data, made available by a given public administration. 
Therefore, being classificatory in nature, our proposal differs from state-of-the-art academic contributions actually focused on identifying dimensions and constructs for value generation of open government data [7], as well as from scholars interested in measurement issues of capabilities [8]. While considering these contributions as potentially having a relevant impact on the evolution of the framework, at present, we have decided to focus our attention on dimensions and indicators from institutional systematic settings, already applied in policy making and analysis.

The paper is structured as follows. First, an analysis of the background literature and perspectives is provided to introduce the research motivations. Then, we outline the research method followed, further detailing how the proposed framework has been developed. Subsequently, figures are presented from the framework application on open government data local initiatives of the municipalities of Florence, Rome, London, as well as a national one for the Tunisian Ministry of Interior. Finally, the Conclusions provide a summary of the results of the research, as well as an outline of the current limitations, guiding future work.

\section{Background and Motivations}

Stage models, guiding public institutions in their paths towards open government data, have been proposed in the literature [9-12], as well as studies regarding the impact of the convergence of open data and, for example, mobile applications on citizens' empowerment and the consequent emergence of ecosystems of citizens, vendors and developers around open government data [13,14]. Finally, a trend of research is actually focusing on the evaluation of open government data, economic, as well as public or social value [15], consequently trying to identify generation mechanisms for the different facets that value can assume when considered at a welfare level [7]. The latter stream of research should be framed in the more general debate on "public value" [16,17], questioning the relevance of market orientation and economic value indicators, such as, the gross domestic product (GDP), for the assessment of public/governmental initiatives [7,18,19]. The debate has generated a vast literature, focusing on the definition of the concept of public value, its indicators and measurement techniques, a discussion of which is out of the scope of this paper, and we refer the reader to other contributions, such as, e.g., $[4,16,17,20,21]$. However, in what follows, we provide an overview in order to connect public value to social value perspectives, actually applied for open government data initiative evaluation.

Public value can be defined as the value that citizens and their representatives seek in relation to strategic outcomes and the experiences of public services [22,23]. Thus, it can be seen as being related to the achievements of objectives, set by government programs, and the delivery of public services to citizens [21]. As pointed out by diverse authors in the literature [2,3,24,25], public value encompasses a wide range of values, focusing on outcomes rather than outputs, thus deeply considering what has meaning for the constituencies, rather than what a government or public-sector decision-makers presume they care about or need [26]. In particular, Benington [25] has contributed to clarifying the different components and goals of public value, arguing that it requires a shift from asking "What does the public most value?" to "What adds value to the public sphere?" As for this issue, considering the perspective on social value outlined in the Introduction and public administrations as only one of the actors in the public sphere, which includes also actors from the private sectors, we point out that social value, concerning values for the society at large [2], can provide hints regarding public (value) failures 
for the contribution of the public to society [2,27]. Thus, public value is relevant to decision-makers, and it should be framed in a wider understanding of what adds value to the public sphere, the latter considered as "the web of values, places, organizations, rules, knowledge, and other cultural resources held in common by people through their everyday commitments and behaviors, and held in trust by government and public institutions" ([25] p. 43). Accordingly, social value can be seen as one of the values making up public value, in particular when referring to the public sphere.

In addition to the definition of public value, another challenging task concerns its measurement and operationalization, in particular at the level of local decision-makers and managers [28]. As for this issue, Alford and O'Flynn [24] analyze a set of experiences and methods for measuring public value, such as the BBC's manifesto "Building Public Value", developed with the support of The Work Foundation [29], or the public service value model (PSVM), focused on measuring the performance of public administration in terms of how it achieves outcomes, as well as the cost-effectiveness over the years [30]. Furthermore, as reported by O'Flynn [31], an early comprehensive perspective on public value measurement has been presented by Kelly, Mulgan and Muers [32], as an attempt to measure the total benefits coming from government action. The authors identified three key components of public value:

- "Services", which are a way of delivering public value (e.g., garbage collection);

- "Outcomes", which may derive from services, but encompass higher order aspirations (e.g., garbage collection protects public health);

- "Trust”, legitimacy and confidence in government.

A further attempt to support the measurement and evaluation of public value, apart from a financial or cost-benefit utilitarian perspective, has been carried out by Meynhardt [4], proposing a public value scorecard, based on four basic value dimensions: moral-ethical, hedonistic-aesthetical, utilitarian-instrumental and political-social.

However, among the different methods for measuring social value, spanning from cost-benefit analysis/cost-effectiveness analysis to social return on investment assessment, through revealed preferences [33], in what follows, we are going to focus on the "life satisfaction assessment" perspective. As argued by Geoff Mulgan [33], the approach, relatively new and unproven, or better, evolving for the metrics to be considered [8], is highly sensitive to input assumptions and assess initiatives, not considering (only) metrics, such as the gross domestic product (GDP), but the degree of extra income needed to achieve a correspondent advantage in terms of life satisfaction [33]. As for this issue, it is worth noting how Geoff Mulgan notices that, in the public sector, political judgment counts more than cost-benefit assessments [33]. As a consequence, an approach, such as life satisfaction assessment, seems promising to support policy and politically-oriented decision-making, due to its focus is on wellbeing and quality of life [34], where the constructs of what is known as the "capability approach" $[35,36]$ have a significant role as a "multi-purpose framework" for providing the references to key indicators and dimensions [37]. Indeed, the capability approach points out that the relevant information concerns "human functionings" (that is, various states of human beings and the doings or activities that a person can undertake) and "capabilities" (i.e., the opportunities to achieve those states and doings), focusing on what is needed for interpersonal comparisons of wellbeing ("functionings") and on the freedom to pursue wellbeing (“capabilities") [37]. Thus, capabilities are a person's real 
freedom or opportunities to achieve functionings as outcomes; for example, travelling is a functioning, and the real opportunity to travel is the corresponding capability. As a consequence, the capability approach focuses on the ends rather than the means (e.g., goods and services) and on how people differ in their ability to convert means into capabilities or outcomes as functionings $[36,38]$. Therefore, the capability approach is suitable to identify what information should be well-thought-out to assess how well an individual's life is as an account of wellbeing or human development [38].

Taking these issues into account, the current diffusion of open data initiatives seems to be suitable to provide, e.g., policy makers access to the kind of information required for interpreting the actual degree of satisfaction or wellbeing of a given population, as well as individuals. However, as questioned by scholars interested in the social value or welfare effects of increased public information when there is imperfect information [39], there is a trade-off between timely, but noisy information and slow, but more accurate information. Furthermore, public information is a double-edged instrument: on the one hand, it conveys information on the underlying details; on the other hand, it serves as a focal point for the beliefs of the group as a whole. Thus, agents may overreact to public information and, thereby, amplify the damage done by any noise.

Consequently, it is our point that, however open data may provide relevant information to social and public value assessment, currently, a research gap concerns the provision of appropriate analytic classification frameworks suitable to ground it. Indeed, we argue that most of the available portals present and make data available, from a public administration- or e-government-centric perspective (the administrative area or service supposed to be of interest to the citizen, the life event, etc.), or from a target industry's point of view (e.g., agriculture, research and development, etc.) or else from a mixed perspective, thus producing "noise" in the data, which may have a relevant effect on the public sphere and social welfare. Consequently, to identify or assess the social or public value orientation of an open data initiative on the basis of its data set remains a challenging task.

Taking the above issues into account, the goal of the paper is to investigate the different dimensions of a classificatory framework suitable to frame the available data sets in order to support public administrations, as well as constituencies in assessing and benchmarking the social value of open data initiatives. Furthermore, on the basis of the framework, we aim to provide a structured repository of open data sets, described in terms of available social value dimensions and indicators. The framework has been tested on three initiatives, referring to three different countries, Italy, the United Kingdom and Tunisia. The countries have been selected in order to provide a focus on the European and Mediterranean countries, considering also the differences in welfare and legal frameworks (for example, civic law compared with common law countries [40,41]). Finally, it is worth noting that initiatives at the local level have been considered for Italy (the municipalities of Florence and Rome) and the United Kingdom (Municipality of London), while for Tunisia, the focus has been on a national open government data portal, that of the Tunisian Ministry of the Interior (however, the latter also provides data sets on municipalities and local activities). In what follows, we first provide a discussion of the framework and early results, subsequently providing figures and insights from its application on the above-mentioned cases. 


\section{Research Method}

The research presented in this paper follows a design orientation, adopting mixed methods [40]. Indeed, the main objective is the building of a classificatory framework being then implemented in a repository, which should allow one to associate a specific data set with triples of the state-of-the-art dimensions and indicators. Thus, the framework and the repository can be considered among the artifacts types mentioned in the design-science literature [42,43]. Being the topic of open government, data actually related to what Simon referred to as "the complexities of designing artifacts on a societal scale" [44], the framework has both an empirical and interpretative nature, being part of further research aiming to identify a theory based on a classification activity [45]. Finally, the design research has been integrated into a mixed methods perspective through the adoption of Internet-mediated research (IMR) for the collection of data, to improve, revise and provide evidence of the proposed model $[14,46,47]$.

\section{Framework Development}

The framework design and development started in January 2013, and was completed in January 2014, involving a team made up of three core researchers (a senior research fellow, a full professor and a research scientist). Furthermore, the development of the framework has also encompassed data collection activities, which have been carried out with the support of two postgraduate students. The details on the framework development are provided in what follows.

Regarding the classificatory framework design, the activity involved a senior research fellow and a full professor, from January 2013 to September 2013. The selection of the main characteristics making up the classificatory framework started from considering the ones identified and structured by the Organisation for Economic Co-operation and Development (OECD) as the set of comparable wellbeing indicators for advanced and emerging economies [34,48]. However, this set provided mainly an implicit reference to potential corresponding capability dimensions, which we consider relevant to build a classificatory framework for social value assessment.

To this end, an analysis of the literature on the capability approach has been carried out $[8,35-38,49,50]$ to identify a minimum set of capabilities worth considering and associated, first, to the OECD wellbeing dimensions and, then, to their indicators. It is worth noting that the analysis of the literature led to including among the capabilities, also, dimensions of human development, such as the ones reported by Alkire [51], based on the Finnis scheme [52], such as "knowledge", including understanding and education, as well as aesthetic experience. The association was then produced through an analysis and subsequent interpretation of the available definitions, as well as an application of the overall constructs, as they were either capabilities or related to wellbeing. The activity involved the senior research fellow, the full professor and a research scientist, acquainted with the capability approach and open government topics. Regarding validation, first, each participant completed the activity autonomously, and then, a common evaluation was carried out during three common one-hour meetings. The result has been the construction of a number of fixed couples, or cluster, of wellbeing and capability dimensions related to a variable set of wellbeing indicators (in what follows, called "triples"). It is worth noting that the indicators are related to a capability, or else wellbeing dimensions, 
as reported in one of the state-of-the-art sources; thus, once a couple has been formed, it inherits all indicators belonging to one of the associated dimensions.

Consequently, the indicators have been reversely used to test the fitness of the dimensions within the corresponding couple. Finally, an external validation has been provided by an assistant professor, not involved in the project, acquainted with the capability approach and open government topics, reviewing the overall classificatory framework. It is worth noting that dimensions and indicators have not been used for measurement activities [53], but as labels for classifying data sets that refers to the domain through which they can potentially target, e.g., survey methods. Subsequently, the framework has been extended, further considering either the actual classification available on a sample of two websites, the Municipality of Florence and the Municipality of London (e.g., "areas of interest/channels", "categories", etc.) or the title proposed for a data set (as in the case of the Municipality of London). The extension has been produced by an early analysis of the two websites by the senior research fellow and the research scientist. These activities led to the first consolidation of the classificatory framework and the design of the conceptual schema of the repository (shown in Figure 1) supporting the data collection. The design of the conceptual schema was carried out in a common session involving the senior research fellow, the research scientist and the full professor.

Figure 1. Conceptual schema of the repository for data collection supporting the social value framework.

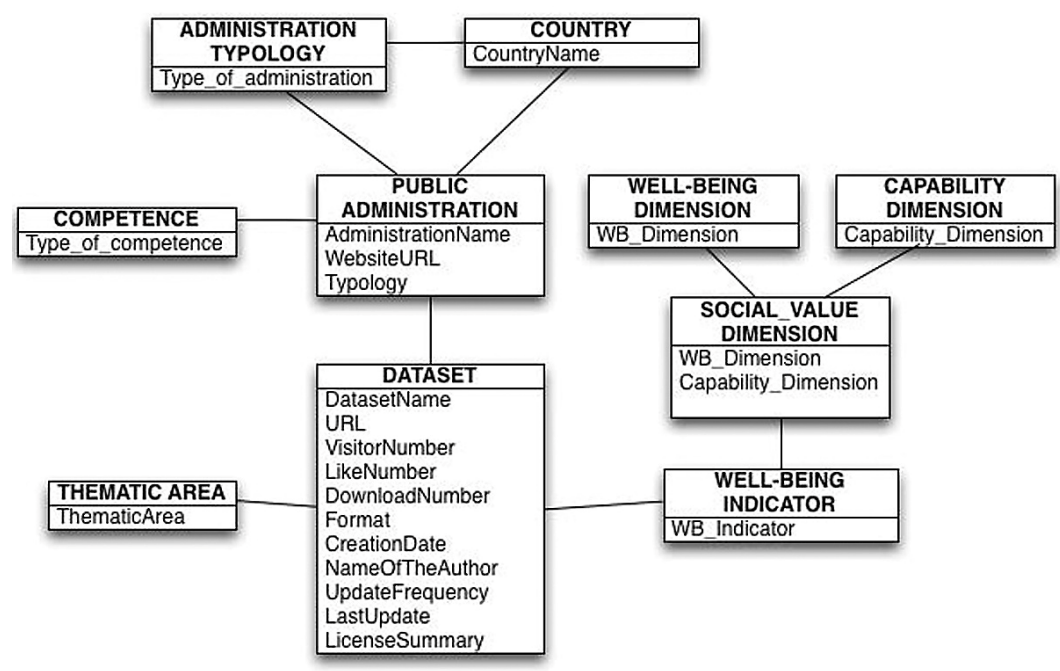

Thus, in addition to the capability approach/wellbeing-related dimensions and indicators, the framework encompasses attributes related to the "number" of available data sets, the "format" of the file within the data sets (csv, excel, pdf, doc, ODS/FODS, RDF, Shape, KMZ, etc.), the "thematic area", creation date, name of the author, update frequency, as well as the last update of the "dataset" and "license summary".

As for data collection, the activity was carried out by a team made up of two postgraduate students, a research scientist, a senior research fellow and a full professor, during a period of four months, from October 2013 to December 2013 (data collection by the two postgraduate students and the research scientist), and January 2014 (revision of model and further data collection by the senior research fellow and the full professor) on two Italian municipalities, Florence and Rome (by the two 
postgraduate students), one in the United Kingdom, London (by the senior research fellow and the research scientist), and one national open government data initiative from a Middle Eastern and North African (MENA) country and the Tunisian Ministry of Interior (by the senior research fellow and the research scientist). The choice was led by the need to compare European local public administrations of different legal traditions, in our case, civic law and common law, and one of the emerging countries from the MENA area. We opted for Tunisia, first considering the attention the country raised during the so-called Arab Spring phenomenon, for the acquaintance of two of the authors with the Tunisian e-government [54] and, finally, for the specificity of the outcomes of the reform process with regard to other MENA Arab countries, leading to a civic-law-oriented constitutional setting. It is worth noting that, however, interesting experiences referred to as open government are noticed for some local Tunisian public administration, such as Sayada [55]; they seem to the authors more focused on, and oriented towards, providing transparent and accountable information on the administration activities through a unique portal, supporting e-participation by constituencies, rather than making accessible open government data through a dedicated platform. Thus, the focus has been shifted towards a national open data portal, that of the Tunisian Ministry of Interior. The data collection activity then shows the need to extend the indicators, revising, partially, the classification, as well as the triples. Consequently, an additional analysis of the literature and a cyclical reclassification of the open government data sets have been carried out by the senior research fellow and the full professor. Furthermore, the classification activities results for the municipalities of Florence and Rome have been discussed and the framework consequently revised through five meetings (from October 2013 to December 2013), involving both the postgraduate students and the research scientist. Furthermore, the results for the Municipality of London and the Tunisian Ministry of Interior were discussed during three meetings, involving the research scientist, the senior research fellow and the full professor (from October 2013 to December 2013). Finally, in early January 2014, two final coding sessions (two hours each), involving the research scientist, the senior research fellow and the full professor, led to the finalized framework, obtaining the final establishment of the part of the classificatory framework related to capability dimensions, as well as wellbeing dimensions and indicators, shown in Table 1.

It is worth noting that what emerged from the classificatory activity is the relevance of capability dimensions in providing a stronger reference to the social value of wellbeing indicators through a granular perspective on their outcomes/functionings. For example, the indicator "Transport places and information" may refer to:

(i) the achievement of the wellbeing dimension "social connections" through the capability "bodily integrity" (i.e., being able to move freely from place to place, secure against violent assault [35], thus with an emphasis on security issues, in this case);

(ii) the achievement of the wellbeing dimension "community" through the capability "control over one's environment" (i.e., being able to participate effectively in political choices by, e.g., reaching the polling station or some political meeting [35], thus, with an emphasis on participation issues, in this case). 
Table 1. Classification scheme for the assessment of the social value of open government data sets.

\begin{tabular}{|c|c|c|}
\hline Wellbeing dimensions & Capability dimensions & Wellbeing indicators \\
\hline Civic engagement & Control over one's environment & $\begin{array}{c}\text { Consultation on rule-making } \\
\text { Voter turnout }\end{array}$ \\
\hline Community & $\begin{array}{c}\text { Affiliation } \\
\text { Bodily integrity } \\
\text { Control over one's environment } \\
\text { Emotions } \\
\text { Knowledge } \\
\text { Spirituality }\end{array}$ & $\begin{array}{c}\text { Volunteering borough } \\
\text { Urban information } \\
\text { Transport places and information } \\
\text { Quality of support network } \\
\text { Demographic indexes } \\
\text { Spirituality information }\end{array}$ \\
\hline Education & Senses, imagination and thought & $\begin{array}{c}\text { Educational attainment } \\
\text { Event information } \\
\text { Job information } \\
\text { Places information } \\
\text { Students skills in math, reading and science } \\
\text { Years in education }\end{array}$ \\
\hline Environment & Other species & $\begin{array}{c}\text { Air pollution } \\
\text { Animal care } \\
\text { Green Quantity } \\
\text { Information about watercourses } \\
\text { Other environmental indicators } \\
\text { Water quality }\end{array}$ \\
\hline Health & Bodily health & $\begin{array}{c}\text { Self-reported health } \\
\text { State of health } \\
\text { Useful information about health } \\
\text { Life expectancy }\end{array}$ \\
\hline & Life & Life expectancy \\
\hline Housing & Life & $\begin{array}{l}\text { Care and treatment of people } \\
\text { Dwelling with basic facilities } \\
\text { Housing expenditure } \\
\text { Rooms per person }\end{array}$ \\
\hline Income & Control over one's environment & $\begin{array}{c}\text { Financial wealth } \\
\text { Heritage and tourism } \\
\text { Household disposable income } \\
\text { Household financial wealth } \\
\text { Number of visitors } \\
\text { Personal earnings } \\
\end{array}$ \\
\hline Jobs & Control over one's environment & $\begin{array}{c}\text { Employment rate } \\
\text { Job information } \\
\text { Job security } \\
\text { Long-term unemployment rate } \\
\text { Number of visitors } \\
\text { Online services information } \\
\text { Personal earnings } \\
\text { Transport places and information }\end{array}$ \\
\hline
\end{tabular}


Table 1. Cont.

\begin{tabular}{|c|c|c|}
\hline Wellbeing dimensions & Capability dimensions & Wellbeing indicators \\
\hline \multirow{6}{*}{ Safety } & \multirow{6}{*}{ Bodily integrity } & Assault rate \\
\hline & & Dangerous natural event \\
\hline & & Homicide rate \\
\hline & & Other crime statistics \\
\hline & & Places of shelter \\
\hline & & Road accidents rate \\
\hline \multirow{3}{*}{ Social connections } & \multirow{2}{*}{ Bodily integrity } & Transport places and information \\
\hline & & Urban information \\
\hline & Control over one's environment & Urban information \\
\hline \multirow{5}{*}{ Work-life balance } & \multirow{2}{*}{ Affiliation } & Employees working very long hours \\
\hline & & Equality of treatment \\
\hline & Appreciation of beauty & Number of visitors \\
\hline & \multirow{2}{*}{ Play } & Number of visitors \\
\hline & & Time devoted to leisure and personal care \\
\hline
\end{tabular}

The final framework (Table 1) includes the characteristics presented on each portal, e.g., the number of "likes" (available for the Municipality of Florence and the Tunisian Ministry of Interior), "five star rating" (available for the Municipality of London and the Tunisian Ministry of Interior), number of "visits" (available for the Municipality of Florence and the Tunisian Ministry of Interior) and number of "downloads" (available for the Municipality of Rome). As for the latter set of characteristics, the difference in their distribution and the actual choice of which among them to include by each public administration led to a hypothesis that will be further investigated in future work. The hypothesis questions the intrinsic nature of these characteristics as a signal of different perspectives on value; for example, a characteristic such as "like" may be considered as related to a public value, such as "what does the public most value?", not explicitly implying an effective usage of the data set by constituencies, which should require a weight, such as the number of downloads, which, on the other hand, implies a different type of action than simple appreciation by the user, as well as a somewhat explicit willingness "to have the data set" as a means for obtaining a certain outcome valuable to the user. Thus, the attribute, "number of downloads", seems a more social value-oriented one, and when considered together with, e.g., the "like" one, may provide an indication on public value, as well as on social value ("What adds value to the public sphere?"). In what follows, details are provided on the research method adopted. Subsequently, results and figures from the framework application are discussed in the Experimental Section.

\section{Framework Application}

In this section, we discuss figures from the framework application on open government data local initiatives of the municipalities of Florence, Rome and London, as well as a national one for the Tunisian Ministry of Interior. Along the four months of experimentation, an overall number of 1742 data sets have been considered, distributed as follows:

- $\quad$ Florence $=425$ data sets; 
- $\quad$ Rome $=564$ data sets;

- $\quad$ London $=558$ data sets;

- $\quad$ Tunisia $=195$ data sets

Table 2 shows the data sets available for each of the considered cases, per triple of wellbeing-capability dimensions and wellbeing indicators. It is worth noting that the wellbeing dimensions having a higher number of data sets are "community" and "civic engagement" (633 and 275 , respectively, namely $36 \%$ and $15 \%$ of the overall data sets). Considering the two triples with the highest number of data sets in Table 2, namely "community-knowledge-demographic indexes" (225 data sets) and "civic engagement-control over one's environment-consultation on rule-making" (211 data sets), "knowledge" and "control over one's environment" result in being relevant capabilities for the considered public administrations.

Table 2. Data sets available on each of the considered cases per triple of capability-wellbeing dimensions and wellbeing indicators.

\begin{tabular}{|c|c|c|c|c|c|c|c|}
\hline $\begin{array}{c}\text { Wellbeing } \\
\text { dimensions }\end{array}$ & $\begin{array}{l}\text { Capability } \\
\text { dimensions }\end{array}$ & $\begin{array}{l}\text { Wellbeing } \\
\text { indicators }\end{array}$ & $\begin{array}{c}\text { No. data set } \\
\text { Florence } \\
\end{array}$ & $\begin{array}{c}\text { No. data set } \\
\text { Rome } \\
\end{array}$ & $\begin{array}{c}\text { No. data set } \\
\text { London } \\
\end{array}$ & $\begin{array}{c}\text { No. data set } \\
\text { Tunisia } \\
\end{array}$ & TOTAL \\
\hline Community & Knowledge & $\begin{array}{c}\text { Demographic } \\
\text { indexes }\end{array}$ & 44 & 33 & 125 & 23 & 225 \\
\hline $\begin{array}{c}\text { Civic } \\
\text { engagement }\end{array}$ & $\begin{array}{c}\text { Control over one's } \\
\text { environment }\end{array}$ & $\begin{array}{l}\text { Consultation on } \\
\text { rule-making }\end{array}$ & 9 & 202 & 0 & 0 & 211 \\
\hline Community & Emotions & $\begin{array}{c}\text { Quality of support } \\
\text { network }\end{array}$ & 42 & 39 & 41 & 35 & 157 \\
\hline Community & Bodily integrity & Urban information & 14 & 44 & 58 & 7 & 123 \\
\hline Community & Affiliation & $\begin{array}{c}\text { Volunteering } \\
\text { borough }\end{array}$ & 31 & 44 & 2 & 0 & 77 \\
\hline Education & $\begin{array}{c}\text { Senses, imagination } \\
\text { and thought }\end{array}$ & Places information & 2 & 10 & 6 & 58 & 76 \\
\hline $\begin{array}{c}\text { Civic } \\
\text { engagement }\end{array}$ & $\begin{array}{c}\text { Control over one's } \\
\text { environment }\end{array}$ & Voter turnout & 5 & 58 & 1 & 0 & 64 \\
\hline Education & $\begin{array}{c}\text { Senses, imagination } \\
\text { and thought }\end{array}$ & $\begin{array}{c}\text { Educational } \\
\text { attainment }\end{array}$ & 30 & 24 & 0 & 0 & 54 \\
\hline Jobs & $\begin{array}{c}\text { Control over one's } \\
\text { environment }\end{array}$ & $\begin{array}{c}\text { Long-term } \\
\text { unemployment rate }\end{array}$ & 0 & 0 & 48 & 6 & 54 \\
\hline Community & $\begin{array}{l}\text { Control over one's } \\
\text { environment }\end{array}$ & $\begin{array}{l}\text { Transport places } \\
\text { and information }\end{array}$ & 6 & 44 & 0 & 1 & 51 \\
\hline
\end{tabular}

Considering now Table 3, the triples of wellbeing-capability dimensions and wellbeing indicators having no data set associated refer to specific facets of capabilities, such as "control over one's environment" and "bodily integrity", focused on personal development and safety; for example, the understanding of the connection between "personal earnings" and "urban information" to support decisions related to housing, jobs opportunities, affiliation (thus, being able to hold property, and having property rights on an equal basis with others, having the right to seek employment on an 
equal basis with others [33]). Furthermore, considering events, such as floods in the U.K. and earthquakes in the central regions of Italy, having data sets on dangerous natural events may provide social value for citizens in these areas.

Table 3. Triples of wellbeing-capability dimensions and wellbeing indicators having no associated data set.

\begin{tabular}{ccc}
\hline Wellbeing dimensions & Capability dimensions & Wellbeing indicators \\
\hline Jobs & Control over one's environment & Personal earnings \\
Safety & Bodily integrity & Dangerous natural event \\
Social connections & Bodily integrity & Transport places and information \\
Social connections & Control over one's environment & Urban information \\
\hline
\end{tabular}

Notwithstanding the above, the analysis of the classified data sets in Tables 2 and 3 enables a preliminary mapping and understanding of the value orientation of the choices made by the considered public administrations as for the data sets that are worth being published, however, without the availability of data on the number of "likes" or "downloads" for all of them, a comprehensive evaluation of their association or reference to public rather than social value for the constituencies is far from being complete. Thus, in what follows, first the case of the three municipalities will be discussed, considering in detail the Florence "likes" and Rome "downloads"-related figure; then, issues related to Tunisia will be explored.

The bar chart in Figures 2 and 3 represents the data sets per capability and wellbeing dimension, respectively. As for the capabilities, "control over one's environment" is still the one having the highest number of data sets for the considered municipalities (367 for Florence, 147 for London and 91 for Rome), while London presents a nearly equal interest in the "knowledge" capability.

Figure 2. Data sets per capability dimensions.

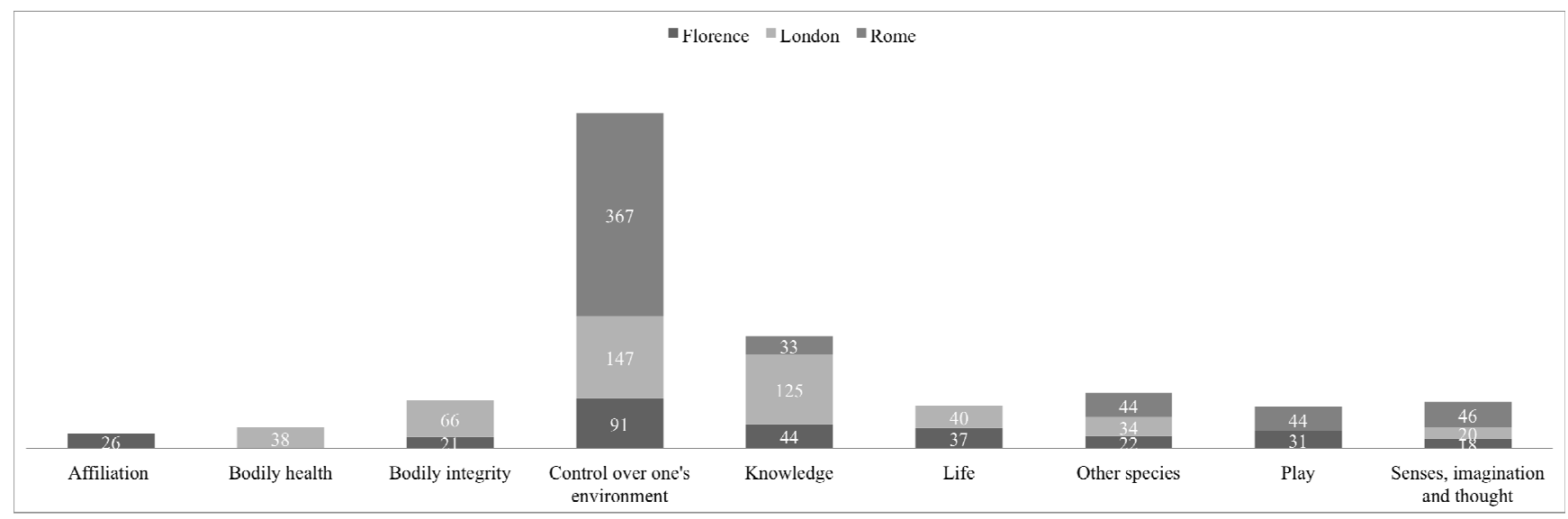


Figure 3. Data sets per wellbeing dimension.

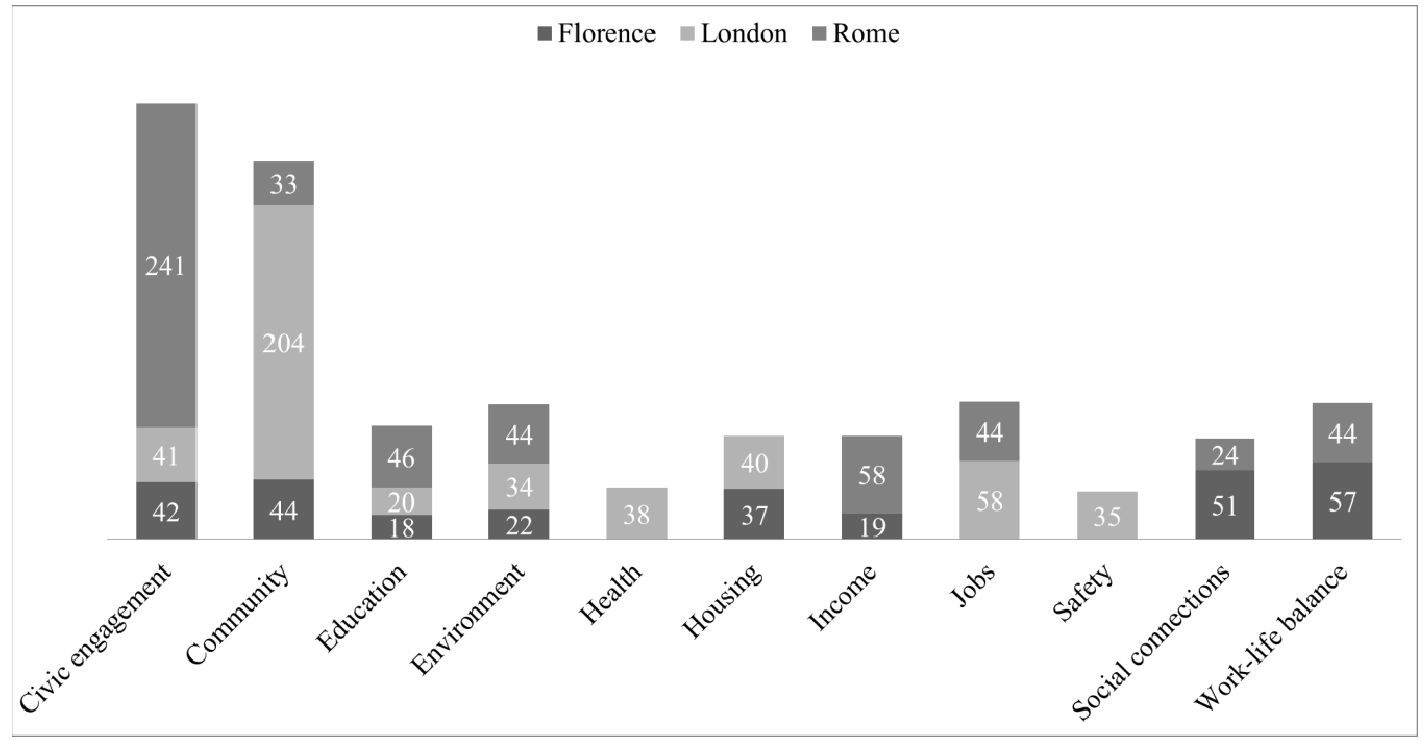

Furthermore, looking at Figure 3, even if the wellbeing dimension with the highest number of data sets is "civic engagement", a difference is emerging between the Italian municipalities and London, the latter having the highest number of data sets for the "community" dimension (204 against 41 for civic engagement). As for London, the wellbeing focus denotes a further attention to public value as social value ("What adds value to the public sphere?"), considering the availability of data sets for indicators oriented towards diversity and freedom from barriers, both in mobility (for example, data sets, such as "travel to "work by bicycle", "ward public transport accessibility levels" for "control over one's environment") and housing or everyday living (for example, data sets, such as "first language spoken at home", "borough diversity in London; report data London happiness scores", "borough subjective personal wellbeing, borough" for "knowledge").

As for the Italian municipalities (see Figure 2), while Florence has the highest number of data sets focused on civic engagement (241), Rome has a nearly equal distribution among "civic engagement" and "community" (42 and 44 data sets, respectively). However, a further analysis should be carried out on the political and social context in order to understand the role of the data set selection, as well as on the choice of the open data portal attributes (e.g., "likes" vs. "downloads") of the political commitment and a consequent explicit open data strategy statement by the mayor (as in the case of Florence [56], whose mayor was appointed as Italian Prime Minister in February, 2014). This analysis would also contribute to differentiating between a "strategy-oriented" (thus, top-down led, as well as focused on appreciation and political approval by constituencies, rather than on the effective use of the data sets by citizens) and an "emergent" perspective (thus, based on the effective use of the data sets by citizens) on open government data initiatives.

Considering the specific use of the "likes" by the Municipality of Florence, the figures in Table 4 show "voter turnout"-related data sets as having the highest rating with regard to other data sets, the latter actually not oriented towards constituency appreciation, but rather to what can be useful to citizens' everyday life. Thus, in this case, a further analysis should be carried out on the role of political variables in the selection of data sets, the choice of the assessment attributes (such as the "likes") and the overall orientation of the open government initiatives towards public or else social value. 
Table 4. "Likes" for the data sets of the "top ten" triples of capability-wellbeing dimensions and wellbeing indicators (Florence).

\begin{tabular}{cccc}
\hline Wellbeing dimensions & Capability dimensions & Wellbeing indicators & No. likes \\
\hline Civic engagement & Control over one's environment & Voter turnout \\
Social connections & Bodily integrity & Transport places and information \\
Environment & Other species & Information about watercourses & 40 \\
Community & Emotions & Quality of support network \\
Environment & Other species & Information about watercourses \\
Safety & Bodily integrity & Road accidents rate & 30 \\
Social connections & Control over one's environment & Urban information \\
Education & Senses, imagination and thought & Job information \\
Community & Knowledge & Demographic indexes \\
Education & Senses, imagination and thought & Years in education & 29 \\
\hline
\end{tabular}

To this end, it is worth considering Table 5, which provides figures on the wellbeing-capability dimensions and wellbeing indicators with a higher number of downloaded data sets, thus providing a different and complementary perspective with regard to the "likes"-oriented one of Florence.

Table 5. "Downloads" of data sets for the "top five" triples of wellbeing-capability dimensions and wellbeing indicators (Rome).

\begin{tabular}{cccc}
\hline Wellbeing dimensions & Capability dimensions & Wellbeing indicators & Downloads \\
\hline Civic engagement & Control over one's environment & Voter turnout & 3998 \\
Safety & Bodily integrity & Road accidents rate & 3563 \\
Community & Knowledge & Demographic indexes & 1958 \\
Civic engagement & Control over one's environment & Consultation on rule-making & 1722 \\
Jobs & Control over one's environment & Job information & 1626 \\
\hline
\end{tabular}

Indeed, the figures in Table 5 show a good balance between a narrow public value orientation towards constituencies (indicators, such as "voter turnout" and "consultation on rule-making" having 3998 and 1722 downloads, respectively) and a focus on public value as a social value for citizens (indicators, such as "road accident rate" and "job information" having 3653 and 1626 downloads, respectively). Additionally, in this case, further analysis investigates whether a formalized open government strategy, political commitment or else the simple availability of digitalized public data and information have an impact on data set selection and the value orientation of the overall initiatives.

Considering now the analyses on the 192 data sets of the Tunisian Ministry of Interior, as shown in Figure 4, "bodily integrity" has the higher percentage of associated data sets (54\%), followed by "control over one's environment" (26\%) and "knowledge" (12\%). The information provided for each data set encompasses attributes, such as the number of "likes", "visits" and the "five star rating", apart from data visualization tools, facilitating access and consultation by interested citizens. However, it is worth noting that most of the data sets for the two latter capabilities refer to the transparency and accountability of the public administration (e.g., the roles and organizational structure of the Ministry, budget allocation, number of complaints received, number of employees of the Ministry and other connected public administrations and demographic statistics). Thus, the data sets related to these 
capabilities entail a narrow orientation towards public value, inherited by the strategy guiding early e-government initiatives carried out in Tunisia before the Arab Spring. It is worth noting that these initiatives have been developed in a perspective of continuity even after the 2011 events by the e-government unit (Unité de l'Administration Électronique en Tunisie), as also witnessed by the official e-government (Administration Électronique) page on the portal of the Présidence du Gouvernement [57].

Figure 4. Data sets per capability dimension (percentages; $N=192$ ).

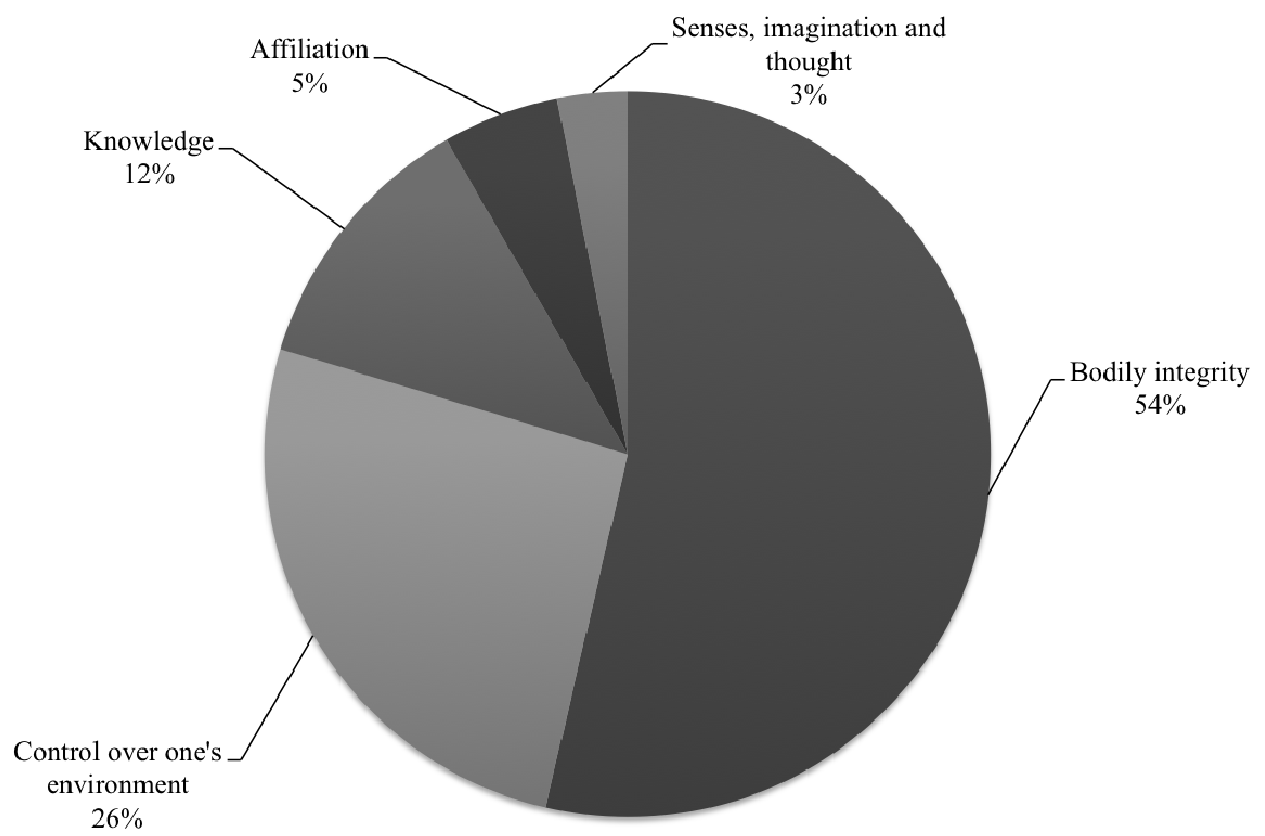

Considering now the "bodily integrity" capability dimension and its related wellbeing dimensions/indicators, Table 6 shows the number of available data sets for each triple. In this case, the focus on data about the road accident rates (58 data sets) and crime statistics (26) points out an orientation towards social value for citizens, also considering the importance of accurate information to empower being able to freely move from place to place, as well as being secure against violent assault, even more in a period of rapid and actually often tumultuous transformation.

Table 6. Data sets for the bodily integrity capability dimension and its related wellbeing dimensions/indicators (Tunisia).

\begin{tabular}{cccc}
\hline Wellbeing dimensions & Capabilities dimensions & Wellbeing indicators & No. data sets \\
\hline \multirow{2}{*}{ Safety } & & Road accidents rate & 58 \\
& \multirow{3}{*}{ Bodily integrity } & Other crime statistics & 26 \\
& & Assault rate & 1 \\
Social connections & & Homicide rate & 1 \\
& & Urban information & 19 \\
\hline
\end{tabular}

Finally, as for the "likes", "visits" and the "five star rating" attributes, it is worth noting a prevalence of indirect information on visits rather than active evaluation by citizens (for example, the data set on the "Budget of the Ministry of Interior 2014" has been visited by 505 users, but with zero 
likes and zero out of five star ratings; or the data set on "local exceptional aid after the revolution" has been visited by 870 users, but again with zero likes and zero out of five star ratings).

\section{Conclusions}

The paper has investigated different dimensions of a classificatory framework suitable to support public administrations, as well as constituencies in assessing and benchmarking the social value of open data initiatives. The framework has been experimented on three initiatives, referring to three different countries, Italy, United Kingdom and Tunisia. The countries were selected to provide a focus on European and Mediterranean countries, also considering the difference in legal frameworks (civic law vs. common law countries). Considering the actual debate on public value, the framework has focused on the social value of outcomes, thus entailing a narrow focus on the strategic question to be answered by policy makers on "What adds value to the public sphere?" [25] and outcomes or socially-oriented values. To this end, the framework has been built by integrating wellbeing dimensions and indicators of capabilities, the latter providing references to the potentially effective use of the available data sets for target functionings, suitable for enabling citizens' lives rather than constituency orientation to vote. However, the goal of the framework at this stage of the research is to classify open government initiatives in a repository, supporting a descriptive analysis of the social value characteristics that may be associated with them. As for this issue, we point out that, while open data may provide relevant information to social and public value assessment, currently a research gap concerns the provision of appropriate analytic classification frameworks suitable to ground it and, consequently, suitable to provide further way for users to access the available data sets, likewise.

Thus, with respect to other approaches discussed in Section 2, the proposed framework aims to introduce a structured and specific focus on social value, adopting state-of-the-art perspectives from the capability approach and wellbeing studies, further exploring one of the perspectives discussed by, e.g., Mulgan [33]. Another contribution is trying to connect dimensions and indicators from the two areas, in order to support a unified classification of open data and open government initiatives. As for the latter, the findings suggest that the adoption of such a classification may provide a different perspective on the available data sets, both to users and decision-makers, often bounded by traditional e-government classification schemes, such as the life event one. Considering, e.g., the results of the application of the framework, public administrations, such as those of the Italian municipalities having a majority of the data set focused on "civic engagement", may decide to extend the number of data sets related to other wellbeing dimensions, such as "community", replicating what has been done abroad by other municipalities with a focus on mobility, housing or everyday living (as in the case of London). Furthermore, considering the state-of-the-art approaches and the debate on public and social value, having mostly a policy-making rather than a strategic perspective on the evaluation of (digital) government initiatives, we believe our contribution differs for the design perspective adopted, which aims to provide a classification, yet framing the access and the choice of the data set under a public or social value perspective. A limitation of the current work concerns the qualitative nature of the building process and the evaluation of what in the paper are called "triples" of wellbeing-capabilities dimensions and wellbeing indicators. An additional quantitative assessment of them should be carried out, as well as a further cluster analysis [45], which are going to be parts of future work. 
Among the contributions of the paper, it is worth noting the positing of the question about the intrinsic nature of attributes associated with open data, such as the number of "likes", "visits", "five star ratings" and number of "downloads", as potential signals of different perspectives on value spanning, e.g., from a narrow public value orientation of the number of "likes", to a prospective social value orientation of the number of downloads. The latter may imply a different type of action than the simply appreciation by the user and a somewhat explicit willingness "to have the data set" as a means of obtaining a certain outcome valuable to the user. However, further investigation is required to verify the above hypothesis, actually emerging from an exploratory activity on the dimensions and indicators suitable to be used to build a social value-oriented classificatory framework. In particular, further analyses should be carried out on the political and social context to understand the role in the data set selection, as well as in the choice of open data portal attributes (e.g., "likes" vs. "downloads") of the political commitment and a consequent explicit open data strategy statement by a decision maker, such as, e.g., a mayor. As stated in previous sections, this analysis would also contribute to differentiate between a "strategy-oriented" and an "emergent" perspective on the value of open government data initiatives. Future work will be focused on investigating these issues in further detail, as well as on the consolidation of the classificatory framework through the application to a homogeneous set of case studies.

\section{Acknowledgments}

The work presented in this paper has been partially supported by the Italian Programma Operativo Nazionale (PON) project PON01_00861 Services and Meta-services for SMART eGovernment (SMART). Furthermore, the authors would like to acknowledge Fabrizio Pontiggia and Aurora Ripamonti for their precious support in the framework application activities.

\section{Author Contributions}

The "Introduction" and "Background and Motivations" sections have been authored by Gianluigi Viscusi, while all the authors contributed equally in all the other sections of the paper.

\section{Conflicts of Interest}

The authors declare no conflict of interest.

\section{References}

1. Janssen, M.; Charalabidis, Y.; Zuiderwijk, A. Benefits, adoption barriers and myths of open data and open government. Inf. Syst. Manag. 2012, 29, 258-268.

2. Jørgensen, T.B.; Bozeman, B. Public values: An inventory. Adm. Soc. 2007, 39, 354-381.

3. Bannister, F.; Connolly, R. ICT, public values and transformative government: A framework and programme for research. Gov. Inf. Q. 2014, 31, 119-128.

4. Meynhardt, T. Public value-Turning a conceptual framework into a scorecard. In Proceedings of the Creating Public Value in a Multi-Sector, Shared-Power World, Minneapolis, MN, USA, 20-22 September 2012. 
5. Merriam-Webster Social. Available online: http://www.merriam-webster.com/dictionary/social (accessed on 12 August 2014).

6. Merriam-Webster Public Available online: http://www.merriam-webster.com/dictionary/public (accessed 12 August 2014).

7. Jetzek, T.; Avital, M.; Bjørn-Andersen, N. Generating Value from Open Government Data. In Proceedings of the 34th International Conference on Information Systems (ICIS 2013), Milan, Italy, 15-18 December 2013; Baskerville, R., Chau, M., Eds.; AIS Electronic Library: Milan, Italy, 2013.

8. Anand, P.; Hunter, G.; Smith, R. Capabilities and well-being: Evidence based on the Sen-Nussbaum approach to welfare. Soc. Indic. Res. 2005, 74, 9-55.

9. Kalampokis, E.; Tambouris, E.; Tarabanis, K. Open Government Data: A Stage Model. In Electronic Government; Janssen, M., Scholl, H.J., Wimmer, M.A., Tan, Y., Eds.; Springer Berlin Heidelberg: Berlin, Heidelberg, Germany, 2011; Vol. 6846, pp. 235-246.

10. Di Maio, A. Gartner Open Government Maturity Model; Gartner, Inc.: Stamford, CT, USA, 2010.

11. Lee, G.; Kwak, Y.H. An open government maturity model for social media-based public engagement. Gov. Inf. Q. 2012, 29, 492-503.

12. Lee, G.; Kwak, Y.H. Open government implementation model: A stage model for achieving increased public engagement. In Proceedings of the 12th Annual International Digital Government Research Conference, College Park, MD, USA, 12-15 June 2011; pp. 254-261.

13. Chun, S.A.; Shulman, S.; Sandoval, R.; Hovy, E. Government 2.0: Making connections between citizens, data and government. Inf. Polity 2010, 15, 1-9.

14. Sandoval-Almazan, R.; Luna-Reyes, L.F.; Rojas-Romero, Y.; Gil-Garcia, J.R.; Luna, D.E. Open government 2.0: Citizen empowerment through open data, web and mobile apps. In Proceedings of the 6th International Conference on Theory and Practice of Electronic Governance, Albany, NY, USA, 22-25 October 2012; pp. 30-33.

15. Tinholt, D. The Open Data Economy: Unlocking Economic Value by Opening Government and Public Data; Capgemini: Paris, France, 2013.

16. Alford, J. Public Value from Co-production by Clients. In Public Value: Theory and Practice; Benington, J., Moore, M.H., Eds.; Palgrave Macmillan: Basingstoke, UK, 2011.

17. Benington, J.; Moore, M.H. Public Value-Theory and Practice; Palgrave Macmillan: Basingstoke, UK, 2011.

18. Bozeman, B. Public Values and Public Interest: Counterbalancing Economic Individualism; Georgetown University Press: Washington, DC, USA, 2007.

19. Savoldelli, A.; Misuraca, G.; Codagnone, C. Measuring the Public value of e-Government: The eGEP 2. 0 model. Electron. J. e-Government 2013, 11. 373-388.

20. Meynhardt, T. Public value inside: What is public value creation? Int. J. Public Adm. 2009, 32, 192-219.

21. Cordella, A.; Bonina, C.M. A public value perspective for ICT enabled public sector reforms: A theoretical reflection. Gov. Inf. Q. 2012, 29, 512-520.

22. Moore, M.H. Creating Public Value : Strategic Management in Government; Harvard University Press: Cambridge, MA, USA, 1995. 
23. Grimsley, M.; Meehan, A. e-Government information systems: Evaluation-led design for public value and client trust. Eur. J. Inf. Syst. 2007, 134-148.

24. Alford, J.; O'Flynn, J. Making sense of public value: Concepts, critiques and emergent meanings. Int. J. Public Adm. 2009, 32, 171-191.

25. Benington, J. From private choice to public value? In Public Value: Theory and Practice; Benington, J., Moore, M.H., Eds.; Palgrave Macmillan: Basingstoke, UK, 2011; pp. 31-51.

26. Rose, J.; Persson, J.S. e-Government value priorities of Danish local authority managers. In IT Management in Local Government: The DISIMIT Project; Software Innovation, Aalborg University: Aalborg, Denmark, 2012; pp. 27-56.

27. Bozeman, B.; Sarewitz, D. Public value mapping and science policy evaluation. Minerva 2010, $49,1-23$.

28. Williams, I.; Shearer, H. Appraising public value: Past, present and futures. Public Adm. 2011, 89, 1367-1384.

29. Building Public Value: Renewing the BBC for a Digital World; British Broadcasting Corporation: London, UK, 2004.

30. Cole, M.; Parston, G. Unlocking Public Value: A New Model for Achieving High Performance in Public Service Organizations; John Wiley \& Sons: Hoboken, NJ, USA, 2006.

31. O'Flynn, J. From new public management to public value: Paradigmatic change and managerial implications. Aust. J. Public Adm. 2007, 66, 353-366.

32. Kelly, G.; Mulgan, G.; Muers, S. Creating Public Value: An Analytical Framework for Public Service Reform; Discussion Paper; the Cabinet Office Strategy Unit, United Kingdom: London, UK, 2002.

33. Mulgan, G. Stanford Social Innovation Review; Stanford University: Stanford, CA, USA, 2010; pp. 38-43.

34. The Organisation for Economic Co-operation and Development (OECD). How's Life?: Measuring Well-Being; OECD: Paris, France, 2011.

35. Nussbaum, M.C. Creating Capabilities-The Human Development Approach; The Belknap Press of Harvard University Press: Cambridge, MA, USA, 2011.

36. Sen, A. Inequality Re-Examined; Clarendon Press: Oxford, UK, 1992.

37. Robeyns, I. The Capability Approach. Available online: http://plato.stanford.edu/archives/ sum2011/entries/capability-approach/ (accessed on 14 August 2014).

38. Robeyns, I. The capability approach: A theoretical survey. J. Hum. Dev. 2005, 6, 93-117.

39. Morris, S.; Shin, H. Social value of public information. Am. Econ. Rev. 2002, 92, 1521-1534.

40. Esping-Andersen, G. The Three Worlds of Welfare Capitalism; Princeton University Press: Princeton, NJ, USA, 1990.

41. Arts, W.; Gelissen, J. Three worlds of welfare capitalism or more? A state-of-the-art report. J. Eur. Soc. Policy 2002, 12, 137-158.

42. March, S.; Smith, G. Design and natural science research on information technology. Decis. Support Syst. 1995, 251-266.

43. Hevner, A.R.; March, S.T.; Park, J.; Ram, S. Design science in information systems research. MIS Q. 2004, 28, 75-105.

44. Simon, H.A. The Sciences of the Artificial; 3rd ed.; The MIT Press: Cambridge, MA, USA, 1996. 
45. Bailey, K.D. Typologies and taxonomies-An Introduction to Classification Techniques; SAGE Publications: Thousand Oaks, CA, USA, 1994.

46. Hewson, C. Internet-mediated research as an emergent method and its potential role in facilitating mixed methods research. In Handbook of Emergent Methods; Hesse-Biber, S.N., Leavy, P., Eds.; Guilford Press: New York, NY, USA, 2008; pp. 543-570.

47. Hesse-Biber, S.; Griffin, A.J. Internet-mediated technologies and mixed methods research: Problems and prospects. J. Mix. Methods Res. 2013, 7, 43-61.

48. The Organisation for Economic Co-operation and Development (OECD). OECD Guidelines on Measuring Subjective Well-Being; OECD: Paris, France, 2013.

49. Zheng, Y. Different spaces for e-development: What can we learn from the capability approach? Inf. Technol. Dev. 2009, 15, 66-82.

50. Hatakka, M.; Lagsten, J. The capability approach as a tool for development evaluation-Analyzing students' use of internet resources. Inf. Technol. Dev. 2011, 18, 23-41.

51. Alkire, S. Choosing Dimensions: The Capability Approach and Multidimensional Poverty; MPRA Paper No. 8862; Munich Personal RePEc Archive: Munich, Germany, 26 May 2008.

52. Finnis, J. Natural Law and Natural Rights; Clarendon Press, Oxford University Press: New York, NY, USA, 1980.

53. Netemeyer, R.G.; Bearden, W.O.; Sharma, S. Scaling Procedures-Issues and Applications; SAGE Publications: London, UK, 2003.

54. Viscusi, G.; Batini, C.; Mecella, M. Information Systems for eGovernment: A Quality-of-Service Perspective; Springer: Berlin, Heidelberg, Germany, 2010.

55. Barraud, C. Sayada, ville pionnière de l'OpenData Available online: http://www.fhimt.com/ 2012/06/26/sayada-ville-pionniere-de-lopendata/ (accessed on 14 August 2014).

56. Rettura, A. Wikitalia e Comune di Firenze, accordo per l'Open Data. Available online: http://www.youtube.com/watch?v=KeakGgK4YZQ (accessed on 14 August 2014).

57. Présidence du Gouvernement Administration électronique. Available online: http://www.pm.gov.tn/pm/article/article.php?id=61\&lang=fr (accessed on 14 August 2014).

(C) 2014 by the authors; licensee MDPI, Basel, Switzerland. This article is an open access article distributed under the terms and conditions of the Creative Commons Attribution license (http://creativecommons.org/licenses/by/3.0/). 